\title{
INYI JOURNAL
}

Research Article

\section{Addressing Syrian refugee adolescents' mental health and wellbeing: Youth-informed policy implications}

\author{
Talia Filler, BSc, MSc, McMaster University
}

\begin{abstract}
Due to the conflict in Syria, Canada has welcomed over 40,000 Syrian refugees since 2015. Of those, approximately $52 \%$ were under the age of 19 , falling into the adolescent age group. Adolescence is critical stage for social, psychological and biological development. As a result, many mental health challenges first emerge during this stage. Given the recent resettlement of Syrian refugees to Canada, it is essential that their mental health is appropriately addressed. This research examined potential policy changes that would help support the mental health and wellbeing of Syrian refugee adolescents given their conceptualizations of mental health. Data was collected from January to March 2018 using semi-structured interviews with Syrian refugee adolescents $(n=7)$ and service providers $(n=8)$ in the Greater Toronto Area. Data analysis was guided by grounded theory. The findings recommend youth-informed strategies for policy makers, service providers and researchers on how to effectively address Syrian adolescents' mental health.
\end{abstract}

Keywords: Refugee Adolescent, Youth, Mental Health, Policy, Syria.

\section{Introduction:}

Since 2011, there has been ongoing conflict in Syria, which is regarded by many as the largest humanitarian emergency of our time. The conflict has resulted in the displacement of over 11 million people (Citizenship and Immigration Canada [CIC], 2017b; CIC 2017c; Lifeline Syria, 2015). The Canadian government responded to this conflict by welcoming over 40,000 Syrian refugees to Canada starting in 2015 (CIC, 2018a). Syrian refugees resettled to Canada as either Government-Assisted Refugees (GARs), Privately Sponsored Refugees (PSRs) or Blended Visa Office-Referred Refugees (BVORs) (CIC, 2017). Further information regarding the different types of refugees can be found in Table 1.

Approximately $52 \%$ of Syrian refugees that came to Canada were under the age of 19 (Citizenship and Immigration Canada, 2017c, 2017b; Lifeline Syria, 2015). Adolescents, which are individuals between the ages of 10 and 19, experience key developmental changes during this life stage. As a result, mental health challenges often first emerge during adolescence (Alderman, Freeman, \& Lobach, 2017). Mental health is defined by the World Health Organization (WHO) as "a state of well-being in which the individual realizes his or her own potential, can cope with the normal stresses of life, can work productively and fruitfully, and is able to make a contribution to her or his own community" (WHO, 2004). For refugee adolescents, they experience both normal adolescent stress, as well as migration related stress, which increases their vulnerability (Fazel, Reed, Panter-Brick, \& Stein, 2012).

In order to appropriately address Syrian adolescents' mental health, their conceptualizations of mental health must first be understood. In addition, policies and practices need to reflect adolescents' conceptualizations to ensure they are effectively targeting adolescents' mental health needs. The purpose of this article is to present youth-informed policy implications and recommendations emerging from Syrian refugee adolescents' conceptualizations of mental health to create effective supports and services. The reported findings are part of a larger study that looks at multiple factors that influence Syrian refugee adolescent mental health. 


\section{INYI JOURNAL}

\section{Table 1}

Information regarding types of refugees in Canada and related definitions.

\begin{tabular}{lll}
\hline Term & Definition \\
\hline $\begin{array}{l}\text { Blended Visa } \\
\text { (BVOR) }\end{array}$ & Office-Referred & $\begin{array}{l}\text { Refugees whose initial resettlement is supported by both the Government of Canada and } \\
\text { private sponsors (CIC, 2017). BVORs are identified by UNHCR and are matched with } \\
\text { private sponsors in Canada by Canadian Visa Officers. There are around 4,000 Syrian } \\
\text { refugees supported as BVORs in Canada (CIC, 2017b). }\end{array}$
\end{tabular}

Government Assisted Refugee Refugees whose initial resettlement in Canada is entirely supported by the Government (GAR) of Canada or Quebec (CIC, 2017). GARS are referred by UNHCR to Canada for settlement and are then screened by representatives from Canada. GARs are usually among the most vulnerable refugees. Currently, there are over 21,000 refugees supported as GARs in Canada (CIC, 2017a).

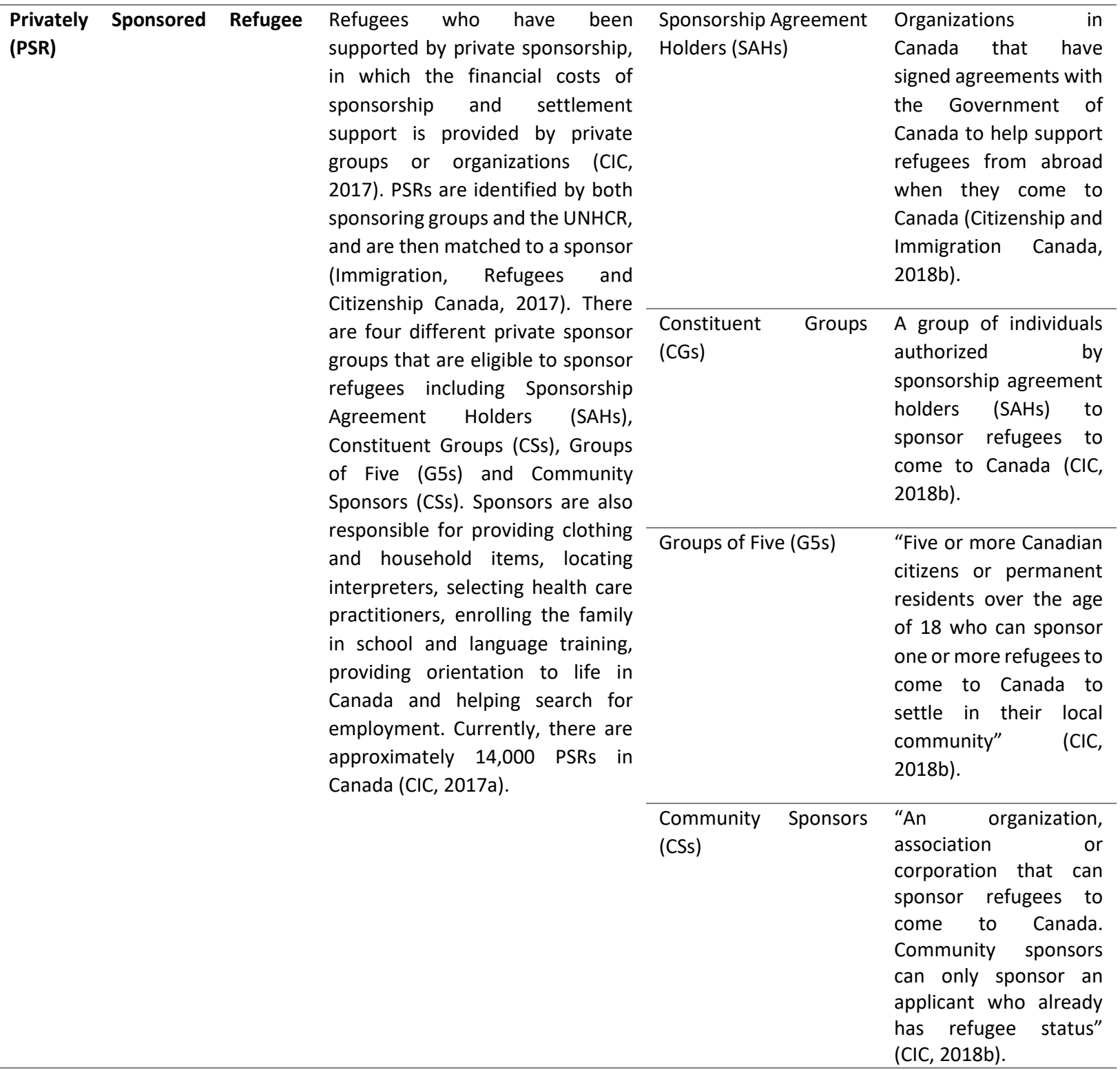




\section{Description of Initiative}

Methods:

This article reports on 7 face-to-face interviews conducted with Syrian refugee adolescents and 8 face-to-face interviews conducted with service providers in the Greater Toronto Area (GTA) between January and March 2018. Interviews focused on adolescents' general understanding of the term mental health. Adolescent participants were between the ages of 16 and 19, had moved to Canada less than 5 years ago and spoke English. Service providers were those who worked directly with Syrian adolescents and represented several different fields including social workers, youth advisors, youth mentors, settlement workers and psychiatrists. Service provider experiences ranged from one year to 20 years in the field. Each interview lasted between 30 and 70 minutes. Before beginning the interviews, informed consent was obtained, and the Participant Information Sheet was reviewed in detail. This study was approved by the Hamilton Integrated Research Ethics Board (HIREB) in December 2017.

\section{Syrian Adolescents' General Conceptualizations of Mental Health}

Through interviews with refugee adolescents and service providers, it was clear that Syrian adolescents were not very familiar with the term mental health. Those who had heard of the term discussed the stigmatization associated with it, which limited them from engaging with the term and related systems used by service providers and institutions in Canada. However, when appropriately framed and expressed using alternative descriptors such as stress, pressure and comfort, adolescents were much more receptive to the concept. Programs and services labelled with appropriate terms may better target Syrian adolescents, leading to their increased engagement and integration into mental health supports and programs. Increased engagement in these programs, and openness to discussing mental health, will allow the mental health needs of Syrian adolescents to be better understood and appropriately addressed.

\section{Policy Implications}

The current policy recommendations were determined after gaining Syrian refugee adolescents' conceptualizations of mental health to assist policy makers, service providers and researchers in strengthening their work with Syrian refugee adolescents. These youth-informed recommendations include appropriately framing mental health programs, increasing parental involvement, improving employment/volunteer opportunities and funding-related changes.

\section{Appropriate framing of mental health in program and service design:}

The ways in which mental health is framed influences how people respond to and understand the concept itself. The stigmatized nature of the term mental health often limits adolescents from engaging with the term and related systems. However, when appropriately framed using words such as stress pressure and comfort, adolescents are much more receptive to the concept. Programs and services labelled with appropriate mental health terminology might better target Syrian adolescents.

Effective program and service labelling starts at the policy level. Previous research examined how mental health policy framing shifted overtime in Scotland (Sturdy, Smith-Merry, \& Freeman, 2012). Before 1990 , mental health was framed around the concept of illness and was oriented towards providing treatment for those who were ill. However, since 1990, the framing has shifted towards recognizing that mental health is important for all. The ways in which problems are framed influence what the solutions will be. In their study, framing mental health as more than an illness broadened the scope of mental health policy to include social, emotional and psychological supports (Sturdy et al., 2012). This case demonstrates the importance of mental health framing and their subsequent policy implications. In Canada, mental health is framed similarly to Scotland's framing (Canadian Mental Health Association, 2018). Adolescent perspectives need to 
be considered and included in mental health framing so that Canadian policy makers can effectively label and promote services.

\section{Increased parental engagement in programs and services for adolescents:}

Adolescents expressed the critical role their parents play in supporting good mental health. Syrian adolescents discussed their involvement in extracurricular programs and the influence that these programs had on supporting good mental health and wellbeing. They attributed their involvement in these programs directly to their parents, as it was their parents who had heard of the programs and encouraged the adolescents to become involved. Adolescents also discussed the ability to confide in their parents during difficult times, as they could trust them more than anyone else. However, despite the increasing recognition that parents have a significant influence on their children's learning and development, service providers tend to be reluctant in soliciting parental involvement. Parents and service providers often assume that young people in their late teenage years want more independence, which is a more westernized understanding of the adolescent development period (Fan \& Williams, 2010; Hill \& Taylor, 2004). However, Syrian adolescents expressed the value in parental involvement. Greater efforts are needed to increase parental involvement in academic and non-academic programming for adolescents.

\section{Increase employment and volunteer opportunities for Syrian adolescents:}

Many adolescent participants in this study were involved in employment or volunteer opportunities in Canada. They discussed how these opportunities were critical in increasing their self-efficacy and selfesteem. These opportunities allowed them to improve their English proficiency while developing relationships with other young people. The benefits that volunteer and employment opportunities offer needs to be widely recognized. Specifically, opportunities that are not limited by language barriers should be considered for the Syrian refugee group.
The importance of increasing volunteer and employment opportunities is supported by a recent study published by the Canadian Medical Association Journal. Dutton and colleagues (2018) found than an increase in spending on social services positively influenced population health measures in Canada at the provincial level. Funds supporting social programming should be increased to better support the health of Syrians and other adolescents. Increased social spending will provide more employment and volunteer opportunities for Syrian adolescents, which in turn will support their mental health and wellbeing.

\section{Consistent and long-term funding for service providers:}

Service providers indicated that being given shortterm work contracts made it difficult to support Syrian adolescents' wellbeing in the long-term. Shortterm contracts were often given to settlement workers and child and youth workers who worked with the Syrian refugee population. Short-term contracts create a great deal of uncertainty for service providers as to whether or not their contracts will be extended. They noted that this limits ongoing planning and engagement with students and schools. The need to shift funding from project-based funds and short-term contracts is supported by previous research (Access Alliance, 2017). Creating long term contracts will allow refugee adolescents to be better supported.

\section{Conclusions}

Syrian refugee adolescents are a particularly vulnerable group. In addressing their health needs, it is essential that their perspectives are solicited and shared with service providers and policy makers. Understanding their conceptualizations of mental health allowed for potential gaps in policy and service provision to be recognized. The suggested policy recommendations can be applied to other refugee groups to ensure they are receiving effective care. Addressing adolescent health needs will ensure they have positive health outcomes both now and later in life. 


\section{Acknowledgements}

I would like to acknowledge my Master's thesis supervisor Dr. Olive Wahoush and committee members Dr. Kathy Georgiades and Dr. Nazilla Khanlou for their valuable contributions to my research. I would also like to thank the community organization and participants for their support thoughtful contributions.

\section{Contact information: tali.filler@gmail.com}

\section{REFERENCES}

Access Alliance. (2017). Refugee health and resettlement: Lessons learned from the Syrian response. Retrieved from: http://accessalliance.ca/wpcontent/uploads/2017/06/SyrianResettlem ent_ResearchHighlightsReport_2017.pdf

Alderman, E. M., Freeman, K. L., \& Lobach, K. S. (2017). Improving adolescent access and services in a large primary care network: Report of a 10 year project. International Journal of Adolescent Medicine and Health, 0(0). Retrieved from: http://doi.org/10.1515/ijamh-2016-0163

Canadian Mental Health Association. (2018). Child and youth - Access to mental health promotion and mental health care. Retrieved April 28, 2018, from https://cmha.ca/documents/child-youthaccess-mental-health-promotion-mentalhealth-care

Citizenship and Immigration Canada. (2017a). \#WelcomeRefugees: Canada resettled Syrian refugees. Retrieved from http://www.cic.gc.ca/english/refugees/welc ome/index.asp

Citizenship and Immigration Canada. (2017b). \#WelcomeRefugees: Key figures. Retrieved from http://www.cic.gc.ca/english/refugees/welc ome/milestones.asp

Citizenship and Immigration Canada. (2017c). Map of destination communities and service provider organizations. Retrieved from http://www.cic.gc.ca/english/refugees/welc ome/map.asp

Citizenship and Immigration Canada. (2017d). Supporting Syrian refugees: Open intake process for new Resettlement Assistance Program Centres. Retrieved November 23, 2017, from:

http://www.cic.gc.ca/english/department/g rants-contributions-funding/syguidelines.asp

Citizenship and Immigration Canada. (2018a). Canada: A history of refuge. Retrieved February 12, 2018, from https://www.canada.ca/en/immigrationrefugeescitizenship/services/refugees/canadarole/timeline.html

Citizenship and Immigration Canada. (2018b). Sponsor a refugee. Retrieved March 1, 2018, from https://www.canada.ca/en/immigrationrefugeescitizenship/services/refugees/help-outsidecanada/private-sponsorship-program.html

Dutton, D. J., Forest, P. G., Kneebone, R. D., \& Zwicker, J. D. (2018). Effect of provincial spending on social services and health care on health outcomes in Canada: An observational longitudinal study. Cmaj, 190(3), E66-E71. http://doi.org/10.1503/cmaj.170132

Fan, W., \& Williams, C. M. (2010). The effects of parental involvement on students' academic self-efficacy, engagement and intrinsic motivation. Educational Psychology, 30(1), 53-74. http://doi.org/10.1080/0144341090335330 2

Fazel, M., Reed, R. V., Panter-Brick, C., \& Stein, A. (2012). Mental health of displaced and refugee children resettled in high-income countries: Risk and protective factors. The Lancet, 379(9812), 266-282. 
http://doi.org/10.1016/S0140-

6736(11)60051-2

Hill, N. E., \& Taylor, L. C. (2004). Parental and children's involvement academic achievement pragmatics and issues. Current Directions in Psychological Science, 13(4), 161-164. http://doi.org/10.1111/j.09637214.2004.00298.x

Lifeline Syria. (2015). Population profile: Syrian refugees. Retrieved from: http://lifelinesyria.ca/wpcontent/uploads/2015/11/EN-SyrianPopulation-Profile.pdf
Sturdy, S., Smith-Merry, J., \& Freeman, R. (2012). Stakeholder consultation as social mobilization: Framing Scottish mental health policy. Social Policy and Administration, 46, 823-844.

World Health Organization. (2004). Promoting mental health: Concepts, emerging evidence, practice (summary report). Geneva. Retrieved from: http://www.who.int/mental_health/eviden ce/en/promoting_mhh.pdf 